NASA/TM-2008-215286

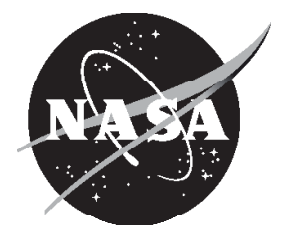

\title{
Cryogenic Fluid Transfer for Exploration
}

\author{
David J. Chato
}

Glenn Research Center, Cleveland, Ohio 


\section{NASA STI Program . . . in Profile}

Since its founding, NASA has been dedicated to the advancement of aeronautics and space science. The NASA Scientific and Technical Information (STI) program plays a key part in helping NASA maintain this important role.

The NASA STI Program operates under the auspices of the Agency Chief Information Officer. It collects, organizes, provides for archiving, and disseminates NASA's STI. The NASA STI program provides access to the NASA Aeronautics and Space Database and its public interface, the NASA Technical Reports Server, thus providing one of the largest collections of aeronautical and space science STI in the world. Results are published in both non-NASA channels and by NASA in the NASA STI Report Series, which includes the following report types:

- TECHNICAL PUBLICATION. Reports of completed research or a major significant phase of research that present the results of NASA programs and include extensive data or theoretical analysis. Includes compilations of significant scientific and technical data and information deemed to be of continuing reference value. NASA counterpart of peer-reviewed formal professional papers but has less stringent limitations on manuscript length and extent of graphic presentations.

- TECHNICAL MEMORANDUM. Scientific and technical findings that are preliminary or of specialized interest, e.g., quick release reports, working papers, and bibliographies that contain minimal annotation. Does not contain extensive analysis.

- CONTRACTOR REPORT. Scientific and technical findings by NASA-sponsored contractors and grantees.

- CONFERENCE PUBLICATION. Collected papers from scientific and technical conferences, symposia, seminars, or other meetings sponsored or cosponsored by NASA.

- SPECIAL PUBLICATION. Scientific, technical, or historical information from NASA programs, projects, and missions, often concerned with subjects having substantial public interest.

- TECHNICAL TRANSLATION. Englishlanguage translations of foreign scientific and technical material pertinent to NASA's mission.

Specialized services also include creating custom thesauri, building customized databases, organizing and publishing research results.

For more information about the NASA STI program, see the following:

- Access the NASA STI program home page at http://www.sti.nasa.gov

- E-mail your question via the Internet to help@ sti.nasa.gov

- Fax your question to the NASA STI Help Desk at 301-621-0134

- Telephone the NASA STI Help Desk at 301-621-0390

- Write to: NASA Center for AeroSpace Information (CASI) 7115 Standard Drive Hanover, MD 21076-1320 
NASA/TM-2008-215286

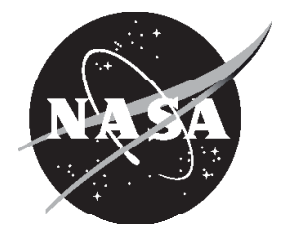

\section{Cryogenic Fluid Transfer for Exploration}

David J. Chato

Glenn Research Center, Cleveland, Ohio

Prepared for the

22nd Space Cryogenics Workshop

sponsored by the Cryogenic Society of America and NASA Marshall Space Flight Center Huntsville, Alabama, July 11-13, 2007

National Aeronautics and

Space Administration

Glenn Research Center

Cleveland, Ohio 44135 
Trade names and trademarks are used in this report for identification only. Their usage does not constitute an official endorsement, either expressed or implied, by the National Aeronautics and Space Administration.

Level of Review: This material has been technically reviewed by technical management.

Available from

NASA Center for Aerospace Information 7115 Standard Drive

Hanover, MD 21076-1320
National Technical Information Service 5285 Port Royal Road Springfield, VA 22161

Available electronically at http://gltrs.grc.nasa.gov 


\title{
Cryogenic Fluid Transfer for Exploration
}

\author{
David J. Chato \\ National Aeronautics and Space Administration \\ Glenn Research Center \\ Cleveland, Ohio 44135
}

\begin{abstract}
This paper discusses current plans and issues for exploration that involve the use of cryogenic transfer. The benefits of cryogenic transfer to exploration missions are examined. The current state of the art of transfer technology is reviewed. Mission concepts of operation for exploration are presented and used to qualitatively discuss the performance benefits of transfer. The paper looks at the challenges faced to implement a cryogenic transfer system and suggest approaches to address them with advanced development research. Transfer rates required for exploration are shown to have already been achieved in ground test. Cost-effective approaches to the required on-orbit demonstration are suggested.
\end{abstract}

\section{Benefits of Cryogenic Fluid Transfer Technology}

Cryogenic fluid transfer is a subject of great interest to many spacefarers. Effective human exploration of the Solar System will require refueling in microgravity with large quantities of cryogenic propellants. Figure 1 shows an artist's concept of space refueling in low earth orbit (LEO). Effective use of Lunar-produced hydrogen and oxygen will require microgravity transfer of propellant at the EarthMoon libration point L1 or Lunar orbit. Although modest quantities of noncryogenic propellant are transferred routinely, the unique properties of cryogens and the much larger quantities of required propellant make the prior techniques ineffective for microgravity cryogenic refueling (ref. 1).

Cryogenic fluid transfer allows the reuse of hardware already in orbit, thus reducing lift mass. Stages initially filled on-orbit can eliminate many of the systems and structural mass required to support and maintain cryogens on the launch pad. Transfer allows tanks on the mission vehicle to be insulated only for the mission rather than the months required to assemble a stage on-orbit. The valving and hardware for cryogenic transfer should be substantially simpler and safer than drop tank designs $(10-$ to $20-\mathrm{cm}$ disconnects that can be checked for leakage versus $43 \mathrm{~cm}$ Shuttle External Tank \{ET\} style valves that must seal instantaneously when the pyrotechnic devices fire to drop the tanks) (ref. 2).

\section{State of the Art}

Resupply of earth storable propellant has been routinely conducted by the Progress module on Russian space stations since 1978. The Russian system is not well documented in the western literature. The most commonly sited source is Feoktistov (ref. 3), but an English translation is not publicly available. Janes (ref. 4) contains a brief but thorough explanation. Another account can be found in Clark (ref. 5). To avoid the problems of phase separation a flexible membrane separates the liquid from the pressurant gas. Then the liquid can be transferred by pressurizing the tank without worrying about ingesting vapor. Drawbacks of this system include life of the membrane, weight and an inability to deal with vapor evolved from the bulk liquid. Nevertheless the Progress module includes resupply tanks holding about $870 \mathrm{~kg}$ of propellant (two tanks of nitrogen tetroxide and two of UDMH hydrazine). This module and system were first used on Saylut 6 on January 20, 1978, and have been used on every space station since, including Mir and International Space Station (ISS). ISS had its first refueling August 2000.

More recent flight experiments have proved valuable in understanding the behavior of fluids in low gravity during transfer. Notable experiments include: Storable Fluid Management Device (SFMD)/Fluid Acquisition and Resupply Experiment (FARE) (refs. 6 to 9), and Vented Tank Resupply Experiment 
(VTRE) (ref. 10), which looked at a vane device to separate gas and liquid during transfer. Figure 2 shows inflow into one of the VTRE tanks during a fluid transfer. The superfluid helium on-orbit transfer (SHOOT) flight demonstration (ref. 11) was fully successful in moving superfluid helium from tank to tank on-orbit. However, its reliance on the unique properties of superfluid helium makes application of these results to other fluids difficult to achieve.

Systems for cryogen propellants such as liquid hydrogen and liquid oxygen have unique challenges. The large scale of the systems for which these propellants are attractive makes any in-tank structure large and complex. No membrane material that can be used at cryogenic temperatures has been identified. Elastomeric membranes fail after a few cycles in liquid oxygen (ref. 12). In addition to the poor cycle life when used in liquid hydrogen, hydrogen diffuses through at an unacceptable rate (ref. 12). At these low temperatures metal membranes suffer from poor flexibility and limited life due to cracking.

During a normal gravity transfer, a top vent is kept open to let out the vapor generated during the transfer process, thereby maintaining a low tank pressure. If the same approach is used in low gravity, the ullage gas may never vent. Instead of venting vapor, large amounts of liquid may be dumped overboard. If liquid is vented from one side, and vapor from the other side, of a nonpropulsive vent, the spacecraft may tumble out of control. The spacecraft can be placed in an artificial gravity field by continuous thruster firing to position the ullage at a vent opening, but this may require dedicated thrusters and additional propellant. In places, such as a depot based at a space station, this thrusting may be impractical due to large system size (refs. 1, 2, and 13). One promising concept for propellants that can be pressurized with their own vapor (such as oxygen and hydrogen) is a procedure known as no-vent fill (refs. 1, 2, and 13). This procedure uses liquid subcooling to re-condense vapor back into the incoming liquid. For tanks, which are warm and dry, a chilldown procedure is used to remove thermal energy from the tank wall, a well as other hardware in close thermal contact with the cryogen, and a sacrificial quantity of cryogen is vented overboard as vapor prior to the start of the transfer. Space venting can also be used to remove noncondensable pressurant such as helium from tanks, prior to the start of the transfer process.

Large-scale cryogenic ground testing programs have demonstrated liquid hydrogen no-vent fill capability with near-flight-weight hardware. Analytical modeling techniques verified by these tests showed that the process can be implemented over a broad range of tank sizes, and modeled to show the effect of size on the process. Tests with a large $\left(4.96 \mathrm{~m}^{3}\right)$ tank are documented by Chato (ref. 14) and Taylor and Chato (ref. 15). These tests demonstrated the impact of varying critical input parameters, such as the liquid inlet mass flow rate and the initial tank wall temperature, on the no-vent fill process. Chato (ref. 16) reports the results of a test series for filling a $2.01 \mathrm{~m}^{3}$ tank with liquid hydrogen without venting. Parameters investigated included inlet saturation pressures, transfer pressures and various starting wall temperatures. Of these tests, only the one run at the highest wall temperature $(132 \mathrm{~K})$ failed to fill the tank. Analytical modeling techniques verified by these tests showed that the process can be implemented over a broad range of tank sizes, and modeled to show the effect of size on the process. Overall modeldata agreement was good except for the tendency of the model to overshoot during the initial wall cool down of the higher starting wall temperature fills.

Flachbart et al. (ref. 17) using an $18.1 \mathrm{~m}^{3}$ tank demonstrated that very high rates of liquid hydrogen transfer (in excess of $4.54 \mathrm{~m}^{3}$ per minute) are achievable with vented fills. However this rate could not be sustained with no-vent fills. The inability to no-vent fill was attributed in part to the significantly heavier that flight-weight tank lid and the resultant high level of residual thermal energy. Recent measurements of liquid position during commercial launch vehicle flights suggest venting may not be as out of the question as previous work as suggested. Kutter et al. (ref. 18) found that once the initial transients in fluid motion had settled out very little settling thrust is required to hold the liquid in position. They also suggest that secondary payloads on commercial vehicles may be a cost effective means for early demonstration of cryogenic fluid transfer technologies. The cryogen transfer operation involves complex thermodynamics, heat transfer and fluid dynamics that are strongly affected by microgravity environments. Therefore, an orbital demonstration is likely to be required before the exploration program will use cryogenic fluid transfer technologies. 


\section{Concepts of Operation for Exploration}

The Exploration Systems Architecture Study (ESAS) (ref. 19) Earth Departure Stage (EDS) reaches orbit roughly 32 percent empty, having used significant propellant just to reach a stable circular orbit. If a Top-Off propellant transfer tanker were available the tanks could be refilled prior to departure, significantly increasing the EDS payload. Alternately, the size of the EDS could be reduced to only contain the 78 percent of propellant required for the earth departure burn. Cost to the EDS would be mainly the weight of the transfer line and its associated valves. The top-off tanker could also replace the propellant lost to boil-off during the wait for the Crew Exploration Vehicle (CEV) to arrive (this time can be as long as 95 days). A more aggressive strategy would be move the insulation required for boil-off mitigation to the tanker vehicle. The tanker would be launched to co-orbit with the EDS and the EDS topped off just prior to the trans-lunar injection burn. This approach would allow the mass that would have been used for insulation on EDS to be used for additional payload. Since the tanker is capable of completing its mission prior to the arrival of the crew it is possible it could be built to un-crewed commercial standards, significantly reducing the amount of margin and redundancy and consequently reducing both weight and cost.

Within the ESAS approach the Lunar Surface Access Module is launched fully loaded with liquid hydrogen and oxygen coupled to the EDS. This system must then wait with the EDS for the CEV to arrive and be either heavily insulated to minimize boil-off or oversized to accommodate boil-off losses. A top-off tanker could refill this stage as well as the EDS (a dedicated LSAM tanker or separate tankers for each stage are probably not operationally efficient.) Even if no tanker is used a transfer system between LSAM and EDS tanks could provide substantial benefit. In general cryogenic storage is more efficient in larger tanks so storing the propellant in the EDS should decrease the total boil-off loss. Also by storing the propellant in EDS the propellant required for descent only has to be insulated for days required for lunar transit rather than the weeks required for CEV Rendezvous. The LSAM tanks could be launched dry and warm eliminating the need for ground hold insulation on LSAM. However, prior to the start of transfer these tanks will have to be chilled down to cryogenic temperatures. The propellant required to chill the tanks down represents another mass loss (ground testing has shown a $149 \mathrm{~kg}$ tank can be chilled down with $14.5 \mathrm{~kg}$ of liquid hydrogen (ref. 20).) Several strategies are available to avoid this loss entirely. One could cool the tanks prior to launch and insulate them to keep them cold. One could cool the tanks on-orbit by using the EDS boil-off to cool them, or coupling them to cryocoolers (especially if the EDS is already using cryocoolers for boil-off mitigation). One does not even have to cool them down to liquid hydrogen temperatures since the majority of energy from the tanks has been removed once they reach liquid nitrogen temperatures.

Transfer operations will also be required for In-Situ Resource Utilization of propellants. Even with the lightweight tank technologies being developed gas storage tanks are not sufficiently lightweight to allow their use for lunar ascent vehicles (ref. 21) so the propellants will have to be liquefied. Although it is conceivable that the In-Situ propellant could be liquefied in the tank which feeds the engine this would mean carrying the mass of the liquefaction system along with the ascent vehicle. A much more practical approach is to liquefy the propellant in a system which remains on the surface and then transfer it to the ascent vehicle shortly before launch. The lunar ascent vehicle may be able to use the lunar gravity to conduct vented transfers. However, further research is required to establish if lunar gravity provides sufficient settling to transfer at reasonable rates.

Preliminary evaluation of concepts for manned Mars missions show six launches of vehicles carrying EDS size stages for one mission (ref. 19). Transfer strategies similar to those proposed for EDS are even more attractive for these larger systems. Since multiple launches are already required to support Mars missions' additional risk imposed by needing to successfully launch transfer tankers is much less than that for the two launch lunar mission. Advanced architecture studies (refs. 22 and 23) also show significant benefits to refueling at L1 prior to traveling deeper into space. Tankers from the lunar surface filled with in-situ propellant (or even just liquid oxygen, the heaviest propellant) rendezvousing with Mars Departure 
Stages (MDS) at L1 could significantly reduce the mass MDS as well. However this scenario would require on-orbit fluid transfer.

\section{Issues of Transfer}

Implementation of on-orbit transfer will require resolution of several issues. Unfortunately additional hardware will be required, but this is mostly plumbing and valving which has already been developed for engine feed systems. We have seen above that the additional hardware weight is more than offset by overall stage mass reduction. The impact and mitigation strategies for the additional launch for tanker vehicles have also been discussed previously. Some pieces of hardware somewhat unique to transfer are disconnects and fluid couplings. Large disconnects and couplings exist but have not yet been qualified for use on-orbit. These flight rated transfer couplings will need to be developed. Unmanned tankers will require some sort of unmanned rendezvous. Soyuz already has an automated rendezvous systems, although it is not always considered reliable (ref. 24). The tele-operated system used as a backup for Soyuz is also an option. Rendezvous technology is being heavily investigated by the DAPRA Orbital Express satellites (ref. 25) as well as being a prime topic of advanced development for exploration given its use on many stages including EDS, CEV, and LSAM.

A study was conducted to compare flow rates demonstrated in experimental rigs (refs. 14 to 17) to the requirements for flight systems. Currently there are no constraints on EDS fill time but most studies tend to recommend a single shift ( $8 \mathrm{hr}$ or less). For propellant quantities required we used the 22 Metric Tons of propellant reported as burned during orbit insertion by the ESAS EDS. The fastest nonvented transfer in Taylor and Chato (ref. 15) is $534 \mathrm{~kg} / \mathrm{hr}$ using a $6.35 \mathrm{~cm}$ diameter pipe. If this is assumed to be the maximum flow rate achievable, transferring the propellant required to top-off the EDS will require $42 \mathrm{hr}$. However, much larger pipes are commonly used on flight systems (for example the STS Main engine Feed is $43.2 \mathrm{~cm}$ in diameter, although such a size is not needed for transfer). Mass flow rate increases roughly as the square of pipe diameter so a $20 \mathrm{~cm}$ pipe would cut the transfer time to $4 \mathrm{hr}$. If we assume we can use the rapid fill techniques of Flachbart et al. (ref. 17) (this will require venting) we can use maximum demonstrated rapid fill rate of $16,000 \mathrm{~kg} / \mathrm{hr}$ with $10.2 \mathrm{~cm}$ diameter pipe to transfer in $1.4 \mathrm{hr}$. Clearly the flow rates required for the transfer are achievable.

One of the criteria for maturing technology out of the advanced development stage (advancing from technology readiness level 4 to 6 for those who prefer technology readiness) is demonstration of its performance in the relevant environment. Unfortunately for fluid transfer one of the relevant environments is low gravity. Technologists have relied on flight tests to develop cryogenic fluid systems since the beginning of space travel. The Saturn IV and Centaur cryogenic upper stage full-scale demonstration flights (refs. 26 and 27) successfully addressed the issues of propellant slosh, settling, and short-term storage/pressure control.

Past experimental attempts to move directly to TRL 6-7 have proved costly. The Cryogenic On-Orbit Liquid Depot Supply Acquisition and Transfer experiment (COLD-SAT) (refs. 28 to 30) was designed to support the Space Exploration Initiative by maturing key technologies to TRL 6. It was based on using a dedicated spacecraft filled with liquid hydrogen as the experiment platform. The concept was only carried through preliminary design but the NonAdvocate Review at the end of the COLD-SAT estimated the cost at about $\$ 200$ million.

Work for the Maturation of Deep Space Cryogenic Refueling project resulted in a design concept for a moderate size flight demonstrator capable of flying as a secondary payload on commercial cryogenic launch vehicles. The top rated MDSCR experiment concept was Centaur Test Bed (CTB) (ref. 31). It proposed a small cryogenic experiment tank attached to the aft end of an existing launch vehicle upper stage. The Cryogenic Propellant Operations Demonstrator (CPOD) payload was developed from CTB to respond the Exploration Systems Mission Directorate's Robotic Lunar Exploration Program (RLEP) Secondary Payload Mission call for proposals (ref. 32). The CPOD cost estimate was well within the $\$ 50$ million cost range called for by RLEP (ref. 32). Although this effort was highly rated, it was not selected due to an RLEP desire to focus on lunar science. Figure 3 shows an artist's concept of this tank and valve 
panel for the experiment. The proposed design attaches to existing hard points on the upper stage and is isolated from the stage propulsion by pyrotechnic valves until after the primary upper stage mission is complete. A highly reliable flight qualified redundant pyrotechnic isolation valve will be installed by the launch vehicle manufacturer into the existing propellant feed line. As such, the experiment can be integrated as a secondary payload on any launch with excess payload capacity and will have minimal impact to the primary payload.

Demonstration of the charge-hold-vent technique for chilldown of warm propellant tanks in low gravity and validation of the No-Vent Fill concept for low-g fluid transfer were key experiments for this payload. The entire experiment is enabled by a transfer of LH2 from the cryogenic upper stage to the CPOD receiver tank The upper-stage cryogens are accessed via the installation of tubing connected to the LH2 feedlines (a similar approach could be use to access liquid oxygen, but hydrogen was selected as the test liquid since it is considered more challenging (ref. 1)). During the nominal mission, a redundant valve isolates the secondary payload from the upper stage's propulsion hardware to minimize risk to the primary payload. Following spacecraft separation these valves are opened allowing the controlled transfer of cryogens to the CPOD receiver tank. As an example CTB calculated the Centaur aft bulkhead contains sufficient space for the installation of a tank as large as 122 by 76 by $76 \mathrm{~cm}$. A receiver tank of this scale is large enough to adequately test most CFM requirements. Existing flight hardware of similar size is already integrated on Centaur.

\section{Concluding Remarks}

Effective human exploration of the solar system will require refueling in low gravity with large quantities of cryogenic propellants. We have seen the benefits to the exploration mission. We have seen that large disconnects and couplings exist but will need to be qualified for use on-orbit. NASA has already undertaken the challenge of developing the orbital rendezvous required. The main stumbling block has been orbital flight demonstration. We have suggested approaches to addressing even this in a cost effective manner.

Most of the technologies required for cryogenic transfer are "near-to-hand". Basic concepts have already been demonstrated (TRL 3-4). What is now required is an advanced development effort to demonstrate these technologies in the relevant environment. Enough time remains before our planned manned Lunar landing in 2020 and manned Mars mission at some unspecified time in the future to bring this technology forward.

\section{References}

1. Chato, D.J., "Technologies for Refueling Spacecraft On-Orbit," AIAA-2000-5107, September 2000.

2. Chato, D.J., "Cryogenic Transfer Options for Exploration Missions," AIAA-91-354, September 1991.

3. Feoktistov, K.P., "Nauchnyy Orbital'nyy Kompleks," (Novoye v zhizni, nauke tekhnike. Seriya Komsmavtika, Astronomiya No 3, 1980), "Znaniye” Press 1980 pp. 1-64.

4. Wilson, A. Ed, Jane's Space Directory Twelfth ed. 1996-1997, Article on Progress pp. 23-24, 1996.

5. Clark, P., The Soviet Manned Space Program, Orion Press pp. 94-96.

6. Kirkland, Z. and Tegart, J., "On-Orbit Propellant Resupply Demonstration," AIAA-84-1342, June 1984.

7. Tegart, J. and Kirkland, Z., "On-Orbit Propellant Resupply Demonstration—Flight Test Results," AIAA-85-1233, July 1985.

8. Dominick, S. and Driscoll, S., "Fluid Acquisition and Resupply Experiment (FARE I) Flight Results," AIAA-93-2424, June 1993.

9. Dominick, S. and Tegart, J., "Orbital Test Results of a Vaned Liquid Acquisition Device," AIAA94-3027, June 1994. 
10. Chato, D.J; and Martin, T.A., "Vented Tank Resupply Experiment—Flight Test Results,” AIAA-972815, July 1997.

11. DiPirro, M., Shirron, P., and Tuttle, J., "On-Orbit Superfluid Transfer: Preliminary Results from the SHOOT Flight Demonstration,” Cryogenics vol. 34 no. 5, 1994.

12. Lark, R.F. "Cryogenic Positive Expulsion Bladders," NASA TM X-1555, April 1968.

13. Chato, D.J, et al. "Cryogenic Fluid Management Technologies for the Space Launch Initiative," IAC02-V.5.05, October 2002.

14. Chato, D.J., "Ground Testing on the Nonvented Fill Method of Orbital Propellant Transfer: Results of Initial Test Series," AIAA-91-2326, June 1991.

15. Taylor, W.J. and Chato, D.J., "Comparing the Results of an Analytical Model of the No-Vent Fill Process With No-Vent Fill Test Results for a $4.96 \mathrm{~m}^{3}$ (175 ft $\mathrm{ft}^{3}$ Tank," AIAA-92-3078, July 1992.

16. Chato, D.J., "Ground Testing for the No-Vent Fill of Cryogenic Tanks: Results of Tests for a 71 Cubic Foot Tank," AIAA-93-1967, June 1993.

17. Flachbart, Robin H, Heydayat, Ali, and Holt, Kimberly A, "Modeling and Test Data Analysis of a Tank Rapid Chill and Fill System for the Advanced Shuttle Upper Stage (ASUS) Concept," Advances in Cryogenics vol. 47 pp. 1284-1291, 2002.

18. Kutter; Bernard F. et al., "Settled Cryogenic Propellant Transfer," AIAA-2006-4436, July 2006.

19. Anon. "NASA's Exploration Systems Architecture Study—Final Report," NASA/TM-2005215062, November 2005.

20. Chato, D.J; and Sanabria, R; "Review and Test of Chilldown Method for Space-Based Cryogenic Tanks," AIAA-91-1843, June 1991.

21. Arif, H., Aydelott, J.C., and Chato, D.J., "Evaluation of Supercritical Storage and Transfer Systems for Future NASA Missions," Journal of Propulsion and Power vol. 8 no. 2, AIAA March 1992.

22. Troutman, P.A, et al. "Orbital Aggregation and Space Infrastructure Systems," IAC-02-IAA.13.2.06, October 2002.

23. Troutman, P.A, et al., "Revolutionary Concepts for Human Outer Planet Exploration (HOPE)" Space Technology and Applications Int. Forum 2003 AIP Conference Proceedings vol. 654; no. 1; pp. 821-828, February 2003.

24. Anon. "Soyuz Launches Progress Cargo Flight to ISS/Automated Rendezvous Tests" http://www.spaceandtech.com/digest/flash2002/flash2002-060.shtml, Space and Tech news flash June 2002.

25. Hastings, D. "Studies to Enable a Paradigm Shift in the Space Enterprise: Astro/Orbital Express; Final Report" Air Force AFRL-VS-PS-TR 2006-1050, January 2006.

26. Anon. "Evaluation of AS-203 Low Gravity Orbital Experiment," Chrysler Corporation January 1967.

27. Lacovic, Raymond F., et al. "Management of Cryogenic Propellants in a Full-Scale Orbiting Space Vehicle," NASA TN D-4571, May 1968.

28. Bailey, W.J. et al., "Cryogenic On-Orbit Liquid Depot Storage, Acquisition and Transfer Satellite (COLD-SAT) Feasibility Studies,” Martin Marietta Space Systems Co., NASA CR 185247, June 1990.

29. Schuster, J.R., Russ, E.J., and Wachter, J.P., "Cryogenic On-Orbit Liquid Depot Storage, and Transfer Satellite (COLD-SAT)" General Dynamics Space systems Division and Ford Aerospace Space Systems Division, NASA CR-185249, July 1990.

30. Rybak, S.C. et al., "Feasibility Study for a Cryogenic On-Orbit Liquid Depot-Storage, Acquisition and Transfer (COLD-SAT) Satellite," Ball Aerospace Systems Group, NASA CR-185248, August 1990.

31. Sakla S., B. Kutter, and J. Wall, "Centaur Test Bed (CTB) for Cryogenic Fluid Management" AIAA2006-4603, July 2006.

32. Anon., "ESMD Robotic Lunar Exploration Program Secondary Payload RFI" archived at http://www.fbo.gov/servlet/Documents/R/1350535, NASA January 2006. 


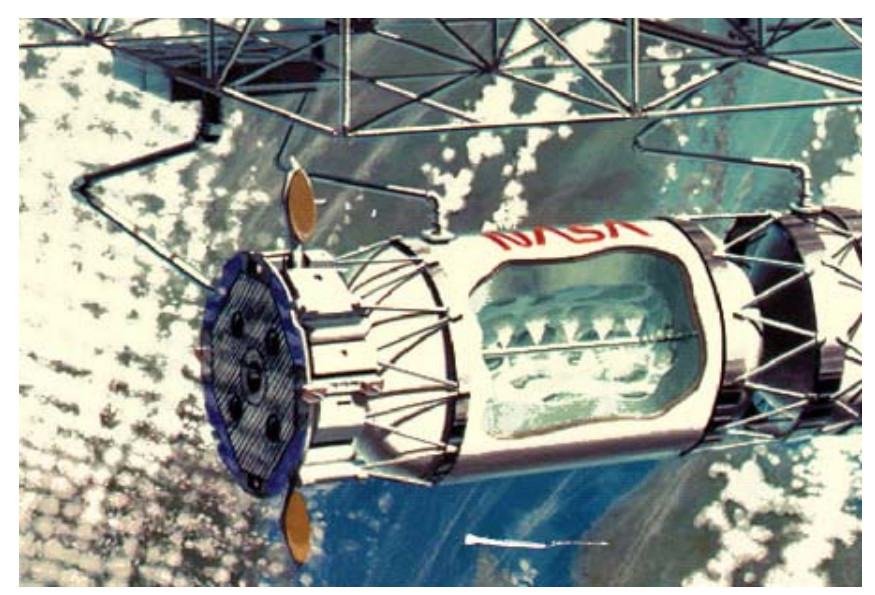

Figure 1.-Artist's concept of a space exploration stage being refueled from a depot in low earth orbit via no-vent fill.

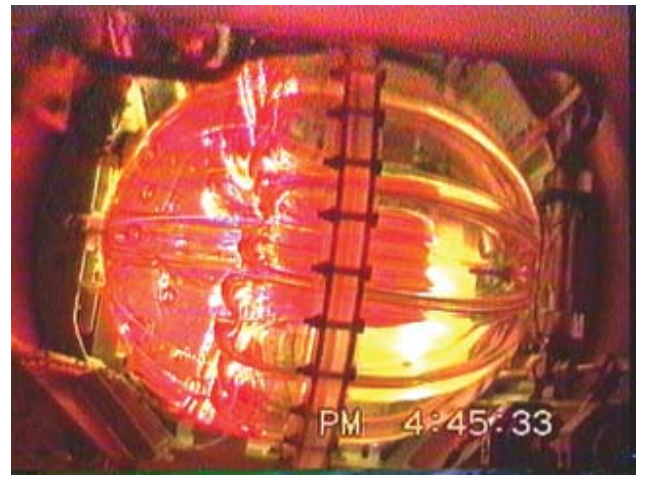

Figure 2.-Vented Tank Resupply Experiment during inflow, exhibiting center post fluid collection phenomena; predicted but unseen until VTRE flight.

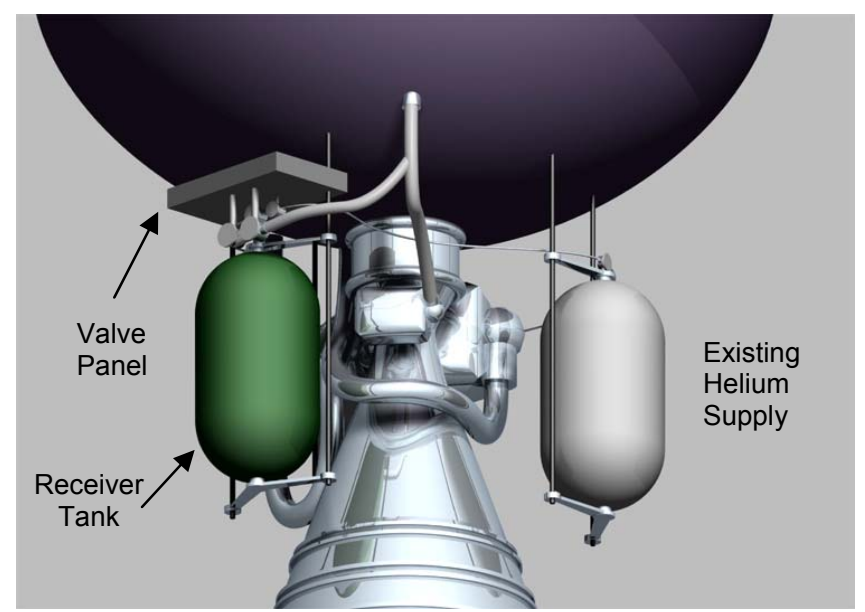

Figure 3.-Artist concept of Cryogenic Propellant Operations Demonstrator (CPOD) based on the Lockheed-Martin Centaur Test Bed (CTB) concept. 


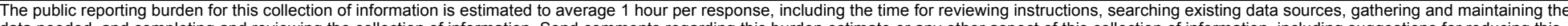

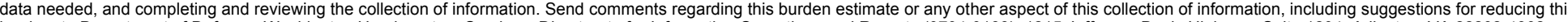

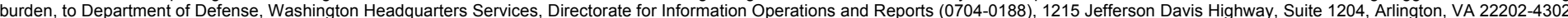

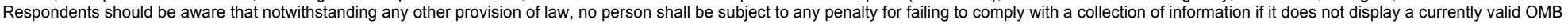
control number.

PLEASE DO NOT RETURN YOUR FORM TO THE ABOVE ADDRESS.
1. REPORT DATE (DD-MM-YYYY)
2. REPORT TYPE

\section{DATES COVERED (From - To)}

01-07-2008

Technical Memorandum

\section{TITLE AND SUBTITLE}

Cryogenic Fluid Transfer for Exploration

5a. CONTRACT NUMBER

5b. GRANT NUMBER

5c. PROGRAM ELEMENT NUMBER

5d. PROJECT NUMBER

6. AUTHOR(S)

Chato, David, J.

5e. TASK NUMBER

5f. WORK UNIT NUMBER

WBS 253225.04.01.02.04.01.03

\section{PERFORMING ORGANIZATION NAME(S) AND ADDRESS(ES)}

National Aeronautics and Space Administration

8. PERFORMING ORGANIZATION

REPORT NUMBER

John H. Glenn Research Center at Lewis Field

E-16556

Cleveland, Ohio 44135-3191

\section{SPONSORING/MONITORING AGENCY NAME(S) AND ADDRESS(ES)}

National Aeronautics and Space Administration

Washington, DC 20546-0001

\section{T0. SPONSORING/MONITORS ACRONYM(S) \\ NASA}

11. SPONSORING/MONITORING REPORT NUMBER

NASA/TM-2008-215286

\section{DISTRIBUTION/AVAILABILITY STATEMENT}

Unclassified-Unlimited

Subject Category: 15

Available electronically at http://gltrs.grc.nasa.gov

This publication is available from the NASA Center for AeroSpace Information, 301-621-0390

\section{SUPPLEMENTARY NOTES}

\section{ABSTRACT}

This paper discusses current plans and issues for exploration that involve the use of cryogenic transfer. The benefits of cryogenic transfer to exploration missions are examined. The current state of the art of transfer technology is reviewed. Mission concepts of operation for exploration are presented, and used to qualitatively discuss the performance benefits of transfer. The paper looks at the challenges faced to implement a cryogenic transfer system and suggest approaches to address them with advanced development research. Transfer rates required for exploration are shown to have already been achieved in ground test. Cost-effective approaches to the required on-orbit demonstration are suggested.

\section{SUBJECT TERMS}

Cryogenics; Low-gravity; Propellant Management; Hydrogen; Oxygen; Fluid acquisition; Space cryogenics

\begin{tabular}{|c|c|c|c|c|}
\hline 16. SECURI & ASSIFICATION & & 17. LIMITATION OF & 18. NUMBER \\
\hline $\begin{array}{l}\text { a. REPORT } \\
\text { U }\end{array}$ & $\begin{array}{l}\text { b. ABSTRACT } \\
\mathrm{U}\end{array}$ & $\begin{array}{l}\text { c. THIS } \\
\text { PAGE } \\
\text { U }\end{array}$ & UU & $\begin{array}{c}\text { PAGES } \\
13\end{array}$ \\
\hline
\end{tabular}

\section{9a. NAME OF RESPONSIBLE PERSON STI Help Desk (email:help@sti.nasa.gov) 19b. TELEPHONE NUMBER (include area code) 301-621-0390}



